\title{
Association between FSHR polymorphisms and polycystic ovary syndrome among Chinese women in north China
}

\author{
Xue-qing Wu • Su-ming Xu • Jun-fen Liu • Xing-yu Bi • \\ Yuan-xia Wu $\cdot$ Jing Liu
}

Received: 17 August 2013 / Accepted: 19 December 2013 / Published online: 5 January 2014

(C) The Author(s) 2014. This article is published with open access at Springerlink.com

\begin{abstract}
Purpose Polycystic ovary syndrome (PCOS) is a common endocrine disorder disease among women in reproductive-age. Since follicle stimulating hormone (FSH) exerts important biological functions, the association between PCOS and FSH receptor (FSHR) polymorphisms attracts wide attention. The aim of this study was to evaluate whether polymorphisms of FSHR at 307 and 680 codons are associated with PCOS patients in China. Methods Patients with PCOS $(n=215)$ and controls $(n=205)$ were recruited from Shanxi Province in north China. They are Han ethnics. Genomic DNA was isolated from the venous blood. The Ala307Thr and Ser680Asn polymorphisms of FSHR were analyzed by polymerase chain reaction-restriction fragment length polymorphism (PCR-RFLP) and direct DNA sequencing. Results The distributions of genotype and allele of Ala307Thr and Ser680Asn polymorphisms of FSHR were not statistically different between the PCOS patients and the controls. Analysis of the frequency of FSHR polymorphisms showed no statistical difference among the PCOS patients with different obesity standards. Although there were no statistical differences in the most of the endocrine parameters including $\mathrm{LH}$, $\mathrm{LH} / \mathrm{FSH}, \mathrm{E} 2, \mathrm{P}$ and $\mathrm{T}$ as well as the clinical pregnancy rate, there were significant differences in the levels of FSH and PRL among PCOS patients carrying different genotypes of Ala307Thr and Ser680Asn polymorphisms.

Conclusion The Ala307Thr and Ser680Asn polymorphisms of FSHR are not associated with PCOS in Han ethnic Chinese women in north China. The FSHR polymorphisms was related to the levels of FSH and PRL but not other PCOS-associated
\end{abstract}

Capsule FSHR polymorphisms in north China women with PCOS.

X.-q. Wu $(\bowtie) \cdot \mathrm{S} .-\mathrm{m} . \mathrm{Xu} \cdot$ J.-f. Liu $\cdot$ X.-y. Bi $\cdot$ Y.-x. Wu • J. Liu Center of Reproductive Medicine, Shanxi Women and Children Health Hospital, No. 13, Xin Min Bei Jie, Xinghualing District, 030013 Taiyuan, Shanxi, China

e-mail: fengye416@126.com endocrine hormones as well as clinical pregnancy rate in PCOS patients of Han Chinese ethnical population.

Keywords Polycystic ovary syndrome $\cdot$ Follicle-stimulating hormone receptor $\cdot$ Genetic polymorphisms $\cdot$ Single nucleotide polymorphisms

\section{Introduction}

Polycystic ovary syndrome (PCOS) is a common endocrine disorder disease among women of reproductive age. The prevalence of PCOS is $5-10 \%$ and the clinical manifestation of the disease is diverse [1]. According to the 2003 Rotterdam criteria [2], the characteristics of PCOS mainly include oligomenorrhea or amenorrhea, hyperandrogenism and polycystic ovary morphology. The pathogenesis of PCOS is not fully understood. However, the influence of heredity and environment is considered to be the potential causative factors for the disease. Recent studies revealed that there are multiple susceptibility genes associated with PCOS, including growth hormone receptor exon 3 [3], CYP11A1 [4] and GnRH [5].

Follicle stimulating hormone (FSH) is an important hormone for women and plays a role in the follicle development, oocyte maturation, and steroidogenesis regulation [6]. It mediates FSH receptor (FSHR) through its biological functions [7]. FSHR belongs to the G-protein coupled receptor family and consists of 10 exons, 9 introns and the promoter region at chromosome 2 p21 [8]. The level of FSH is controlled by FSHR, and aberrant FSHR affects ovary and folliculogenesis [6]. Previous studies revealed a low incidence of gene mutations for the FSHR gene in nature [9]. Single nucleotide polymorphisms (SNP) were identified in the FSHR gene [10, 11]. Among them, Ala307Thr and Ser680Asn polymorphisms in exon 10 have drawn increasing attention. Due to the changes of nucleotide at 307 and 680 loci, which lead to changes of 
corresponding amino acids, FSHR varies in its biological effects. Many studies showed that FSHR polymorphisms at positions 307 and 680 may be even more relevant for clinical practice for the reasons of regulating the ovarian reaction to hormone, controlling ovarian hyperstimulation, changing the menstrual cycle, and causing premature ovarian failure (POF) and PCOS [12]. However, some researches suggested that the results were inconsistent with the interrelationship between FSHR polymorphisms and PCOS. Gut et al. reported that the Ser680Asn of FSHR was associated with PCOS in Korean women, whereas the Ala307Thr was not [6]. On the contrary, a research, done by Dolfin et al., showed that the Ala307Thr of FSHR polymorphism was related to PCOS in Italian women [13]. In addition, Unsal et al. found that the genotye frequencies of the Ala307Thr and Ser680Asn polymorphisms of FSHR were not different between the cases and controls in Turkish adolescent girls [14]. In a recent study, we also found that the association between FSHR polymorphisms and PCOS in China was also lack of consistency [15, 16]. Since these studies were conducted in different geographic regions and with different ethnic groups, the discrepant results suggested the FSHR-PCOS interrelationship to be geography and race specific. In this study, we investigated Ala307Thr and Ser680Asn polymorphisms of the FSHR gene and the relationship between FSHR polymorphisms and PCOS in the Han Chinese women in north China.

\section{Materials and methods}

\section{Subjects}

Both the PCOS patients $(n=215)$ and the controls $(n=205)$ were recruited by Reproductive Medicine Center, Shanxi Women and Infants Hospital, Taiyuan, China between January 2012 and January 2013. All subjects were Han ethnic, from the Shaanxi Province, in north China. The study was approved by the local Medical Ethical Committee and the people of the PCOS and the control was consented.

The patients were selected based on the 2003 Rotterdam criteria [2]. Meanwhile, other diseases which could cause hyperandrogenism, such as congenital adrenal hyperplasia, hypothyroidism, androgen-secreting tumors, Cushing's syndrome, were excluded.
The controls were infertility patients due to tubal and or male factors with normal ovarian function.

All of the patients had been ruled out of thyroid abnormalities, cardiovascular system diseases or other endocrine metabolic disorder disease.

\section{Clinical measurements}

The general medical information was collected and recorded, including the clinical examination results: age, height, weight, waist circumference, hip circumference, menstrual history of fertility, B ultrasound assessment, etc. And the body mass index (BMI) and waist/hip ratio (WHR) were calculated accordingly. The clinical hyperandrogenism was assessed by the modified Ferriman-Gallwey score $(\mathrm{mF}-\mathrm{G}$ score) [17]. Transvaginal ultrasonography was used to identify polycystic ovaries (PCO) on a Aloka Prosound $\alpha 10$ (Tokyo, Japan) ultrasound machine. According to the description of $\mathrm{Xu}$ [18], all the above clinical measurements were completed by two physicians. The mean value of what was calculated.

\section{Biochemical measurements}

On the 3rd to the 5th day of menstrual cycles, blood samples were taken between $8 \mathrm{AM}$ and $9 \mathrm{AM}$ after a 12 -h overnight fast and immediately centrifuged and frozen at $-80^{\circ} \mathrm{C}$ until assayed. For the amenorrhea patients, blood samples were taken on any day of menstruation providing no dominat follicle detected under B-ultrasound. The hormone levels, including folliclestimulating hormone (FSH, Reference Value: $4.5 \sim 11.0 \mathrm{mIU} /$ $\mathrm{ml}$ ), luteinizing hormone (LH, Reference Value:1.7 13.3 mIU/ $\mathrm{ml}$ ), estradiol (E2, Reference Value: $40.7 \sim 220.4 \mathrm{pg} / \mathrm{ml}$ ), progesterone (P, Reference Value: $\leq 0.87 \mathrm{ng} / \mathrm{ml}$ ), prolactin (PRL, Reference Value: $4.1 \sim 28.9 \mathrm{ng} / \mathrm{ml}$ ), and testosterone (T, Reference Value: $9.8 \sim 82.1 \mathrm{ng} / \mathrm{dl}$ ) were measured by AIA-200 ST Automated Immunoassay Analyzer (Tosoh Corporation, Tokyo, Japan). The cut-off level of testosterone $>82.1 \mathrm{ng} / \mathrm{dL}$ was defined as biochemical hyperandrogenism.

Plasma glucose (Reference Value: 3.90 6.10 mmol/L) was detected by the hexokinase (HK) method, and insulin (Reference Value: 0 28.4 uIU/ml) was detected by the chemiluminescence method. The homeostatic model assessment

Table 1 Primers, annealing temperatures, product sizes, restriction enzymes, and allele sizes

\begin{tabular}{|c|c|c|c|c|c|c|}
\hline Polymorphism & Primer sequence $\left(5^{\prime}-3^{\prime}\right)$ & $\operatorname{Tm}\left({ }^{\circ} \mathrm{C}\right)$ & Product size & Restriction enzyme & Allele size & Reference \\
\hline Ala307Thr & $\begin{array}{l}\text { F: 5'-CCTGCACAAAGACAGTGATG-3'; } \\
\text { R: 5'-TGGCAAAGACAGTGAAAAG-3' }\end{array}$ & 55 & 577 & AhdI & $\begin{array}{l}\text { Ala: } 403+174 \\
\text { Thr: } 403+143+31\end{array}$ & {$[19]$} \\
\hline Ser680Asn & $\begin{array}{l}\text { F: 5'-TTTGTGGTCATCTGTGGCTGC-3'; } \\
\text { R:5'-CAAAGGCAAGGACTGAATTATCATT-3' }\end{array}$ & 60 & 520 & BsrI & $\begin{array}{l}\text { Asn: } 520 \\
\text { Ser: } 413+107\end{array}$ & {$[20]$} \\
\hline
\end{tabular}

$F$ forward primer, $R$ reverse primer, $T m$ annealing temperatures, $R$ reference 
Table 2 Baseline characteristics of all subjects

\begin{tabular}{|c|c|c|c|}
\hline Variable & Controls $(n=205)$ & Cases $(n=215)$ & $p$ value \\
\hline Age (year) & $31.06 \pm 4.89$ & $30.02 \pm 4.92$ & $0.163^{\mathrm{a}}$ \\
\hline Weight (kg) & $59.19 \pm 7.75$ & $63.40 \pm 11.31$ & $0.023^{\mathrm{b}}$ \\
\hline Height (cm) & $161.60 \pm 4.45$ & $161.66 \pm 5.70$ & $0.979^{\mathrm{b}}$ \\
\hline BMI $\left(\mathrm{kg} / \mathrm{m}^{2}\right)$ & $22.77 \pm 3.96$ & $24.49 \pm 4.26$ & $0.007^{\mathrm{a}}$ \\
\hline Waist (cm) & $80.50 \pm 7.88$ & $92.38 \pm 9.46$ & $0.058^{\mathrm{a}}$ \\
\hline Hip (cm) & $96.75 \pm 7.52$ & $103.59 \pm 6.92$ & $0.076^{\mathrm{a}}$ \\
\hline WHR & $0.83 \pm 0.06$ & $0.89 \pm 0.07$ & $0.009^{\mathrm{a}}$ \\
\hline Menarche age (year) & $13.66 \pm 1.26$ & $13.04 \pm 1.20$ & $0.001^{\mathrm{b}}$ \\
\hline mF-G score & $8.51 \pm 0.09$ & $8.79 \pm 1.20$ & $0.678^{\mathrm{b}}$ \\
\hline FSH (mIU/ml) & $8.81 \pm 5.96$ & $8.79 \pm 10.09$ & $0.009^{\mathrm{b}}$ \\
\hline LH (mIU/ml) & $5.44 \pm 3.97$ & $7.23 \pm 4.36$ & $<0.001^{\mathrm{b}}$ \\
\hline LH/FSH & $0.81 \pm 0.76$ & $1.04 \pm 4.36$ & $<0.001^{\mathrm{b}}$ \\
\hline $\mathrm{E} 2(\mathrm{pg} / \mathrm{ml})$ & $56.99 \pm 34.51$ & $55.45 \pm 24.82$ & $0.385^{\mathrm{b}}$ \\
\hline $\mathrm{P}(\mathrm{ng} / \mathrm{ml})$ & $0.85 \pm 2.62$ & $2.39 \pm 10.82$ & $0.441^{\mathrm{b}}$ \\
\hline $\mathrm{T}$ (ng/dl) & $37.52 \pm 19.31$ & $54.17 \pm 27.70$ & $<0.001^{\mathrm{b}}$ \\
\hline PRL (ng/ml) & $16.74 \pm 9.72$ & $14.84 \pm 12.32$ & $0.026^{\mathrm{b}}$ \\
\hline Fasting insulin (mIU/ml) & $6.92 \pm 3.57$ & $10.97 \pm 6.45$ & $0.727^{\mathrm{b}}$ \\
\hline Fasting glucose (mmol/l) & $5.13 \pm 0.58$ & $5.53 \pm 0.94$ & $0.015^{\mathrm{b}}$ \\
\hline HOMA-IR & $1.45 \pm 1.13$ & $2.17 \pm 1.65$ & $<0.001^{\mathrm{b}}$ \\
\hline $\mathrm{CHO}(\mathrm{mmol} / \mathrm{l})$ & $4.42 \pm 0.64$ & $4.17 \pm 0.36$ & $0.058^{\mathrm{a}}$ \\
\hline TG (mmol/l) & $1.34 \pm 0.16$ & $1.88 \pm 1.20$ & $0.027^{\mathrm{b}}$ \\
\hline HDL (mmol/l) & $1.43 \pm 0.59$ & $1.20 \pm 0.23$ & $0.022^{\mathrm{a}}$ \\
\hline LDL (mmol/l) & $2.44 \pm 0.44$ & $2.25 \pm 0.15$ & $0.007^{\mathrm{a}}$ \\
\hline
\end{tabular}

$B M I$ body mass index, $W H R$ waist/hip ratio, $m F-G$ score modified Ferriman-Gallwey score, $F S H$ follicle-stimulating hormone, $L H$ luteinizing hormone, $E 2$ estradiol, $P$ progesterone, $T$ testosterone, $P R L$ prolactin, HOMA-IR homoeostasis model assessment, $C H O$ cholesterol, $T G$ triglycerides, $H D L$ highdensity lipoprotein, $L D L$ low-density lipoprotein

${ }^{a}$ Student's $t$-test

${ }^{\mathrm{b}}$ Mann-Whtitney $U$ test

for insulin resistance (HOMA-IR) was calculated as follows: (fasting insulin $\times$ fasting glucose)/22.5. Serum cholesterol (CHO, Reference Value: $\leq 5.2 \mathrm{mmol} / \mathrm{L}$ ), triglycerides (TG, Reference Value: $\leq 1.7 \mathrm{mmol} / \mathrm{L}$ ), high-density lipoprotein-cholesterol (HDL, Reference Value: $>1.03 \mathrm{mmol} / \mathrm{L}$ ) and low-density lipoprotein (LDL, Reference Value: $<3.34 \mathrm{mmol} / \mathrm{L}$ ) levels were measured using the precipitation and enzymatic method.

\section{Genotyping}

Genomic DNA was extracted from heparinized venous blood using E.Z.N.A Blood DNA Kit (Omega, Bio-Tek, Norcross, GA, USA) according to the manufacturer's instructions. Polymerase chain reaction (PCR) was performed in a total volume of $50 \mu \mathrm{l}$ containing $100 \mathrm{ng}$ of genomic DNA, $0.3 \mathrm{M}$ of forward and reverse primers, $0.2 \mathrm{mM}$ of dNTP, 2.5 unit of Taq DNA polymerase, and $2 \mathrm{mM}$ of $\mathrm{MgSO}_{4}$. The PCR amplification was initiated at $94{ }^{\circ} \mathrm{C}$ for $5 \mathrm{~min}$, followed by 30 cycles consisting of denaturing at $94{ }^{\circ} \mathrm{C}$ for $30 \mathrm{~s}$, annealing at $55^{\circ} \mathrm{C}$ (for Ala307Thr) or $60{ }^{\circ} \mathrm{C}$ (for Ser680Asn) for $30 \mathrm{~s}$, and elongation at $72{ }^{\circ} \mathrm{C}$ for $1 \mathrm{~min}$, and a final step at $72{ }^{\circ} \mathrm{C}$ for $10 \mathrm{~min}$. All PCR products were subjected to direct DNA sequencing, and $15 \%$ of PCR products were subjected to restriction enzyme digestion for validation by PCR-restriction fragment length polymorphism (PCR-RFLP). Restriction enzymes Ahd I and Bsr I (all from New England Biolabs, Ipswich, MA, USA) were used for Ala307Thr and Ser680Asn, respectively. Ahd I digestion was performed at $37^{\circ} \mathrm{C}$ for $4 \mathrm{~h}$, followed by inactivation at $65^{\circ} \mathrm{C}$ for $20 \mathrm{~min}$. Bsr I digestion was performed at $65^{\circ} \mathrm{C}$ for $4 \mathrm{~h}$, followed by inactivation at $80{ }^{\circ} \mathrm{C}$ for $20 \mathrm{~min}$. Both PCR and enzyme digested products were evaluated by electrophoresis in $2 \%$ and $4 \%$ agarose gels, respectively. The PCR primers, annealing temperatures, product sizes, restriction enzymes, and allele sizes are shown in Table $1[19,20]$.

Statistical analysis

Statistical analysis was performed using SPSS Statistics Version 13.0. Student's $t$-test or Mann-Whitney $U$ test 
a

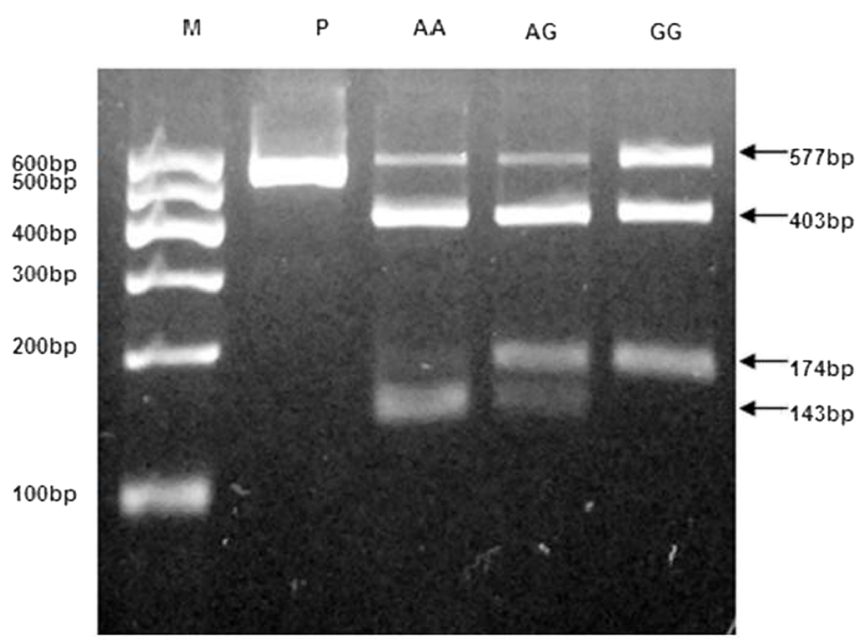

Fig. 1 a Electrophoretogram of DNA fragments for Ala307Thr polymorphisms after digestion with Ahd I. Homozygote A/A was shown by the bands of $403 \mathrm{bp}, 143 \mathrm{bp}$ and $31 \mathrm{bp}$. Homozygote G/G was shown by the bands of $403 \mathrm{bp}$ and $174 \mathrm{bp}$. Heterozygote $\mathrm{A} / \mathrm{G}$ was shown by the bands of $403 \mathrm{bp}, 174 \mathrm{bp}, 143 \mathrm{bp}$ and $31 \mathrm{bp}$. Note that the $31 \mathrm{bp}$ bands

was used to analyze the differences of two continuous variables. ANOVA and Kruskal-Wallis tests were used to analyze the differences among multiple $(>2)$ groups. Genotype frequencies were tested for Hardy-Weinberg equilibrium. Chisquared test was used to analyze the differences in genotype and allele frequencies between PCOS and controls. Results were expressed as percentage and/or mean \pm standard deviation (SD). A $p$-value $<0.05$ was considered statistically significant. Linkage disequilibrium (LD) was estimated using D' and $\mathrm{r}^{2}$ on SHEsis (http://analysis2.bio-X.cn/myAnalysis.php).

a

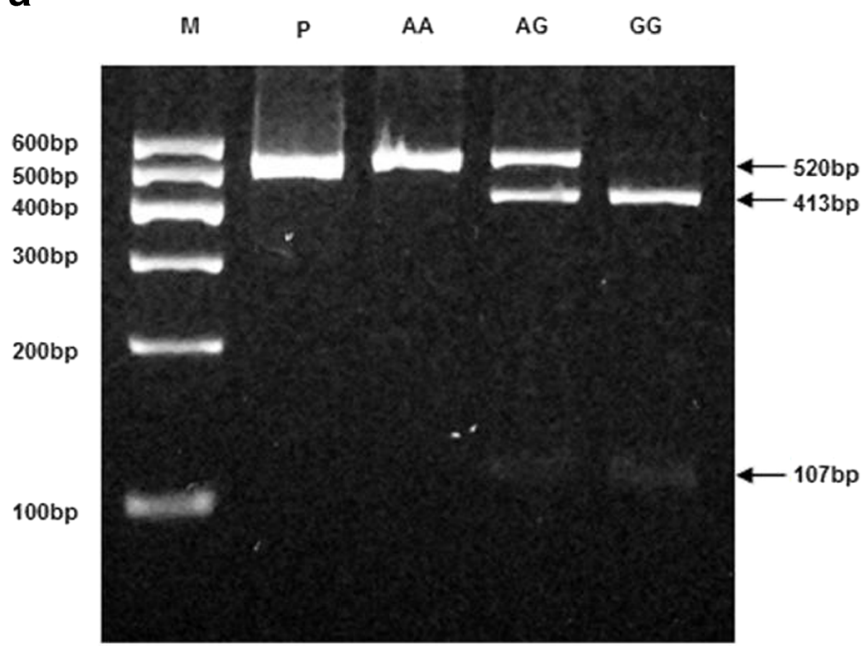

Fig. 2 a Electrophoretogram of DNA fragments for Ser680Asn polymorphism after digestion with Bsr I. Homozygote A/A was shown by the band of $520 \mathrm{bp}$. Homozygote G/G was shown by the bands of $413 \mathrm{bp}$ and $107 \mathrm{bp}$. Heterozygote $\mathrm{A} / \mathrm{G}$ was shown by the bands of $520 \mathrm{bp}, 413 \mathrm{bp}$ and b

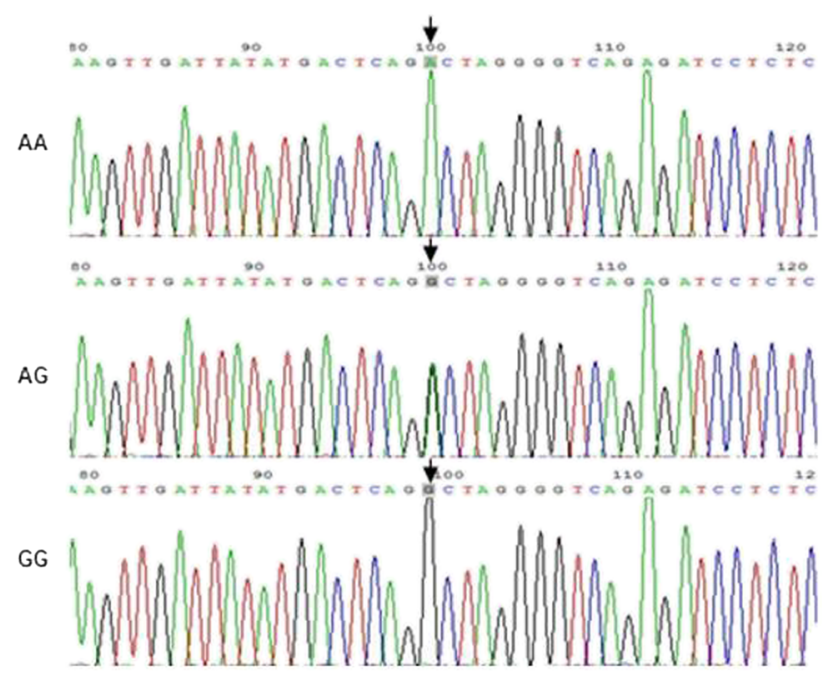

were run off the gel. b DNA sequencing of the Ala307Thr polymorphisms (AA, AG and GG) as indicated by arrows. The lane marked $\mathrm{M}$ is the marker of DNA. The lane marked P is the DNA of PCOS without enzyme digestion

\section{Results}

A total of 215 PCOS patients and 205 controls were recruited in this study. All subjects were Han ethnics in Shanxi Province of north China. The baseline characteristics of the subjects were shown in Table 2. The levels of Weight, BMI, WHR, LH, LH/FSH, T, Fasting glucose, HOMA-IR and TG were higher whereas the levels of Menarche age, FSH, PRL, HDL and LDL were lower in the PCOS patients than in the controls. There were no significant differences between the PCOS

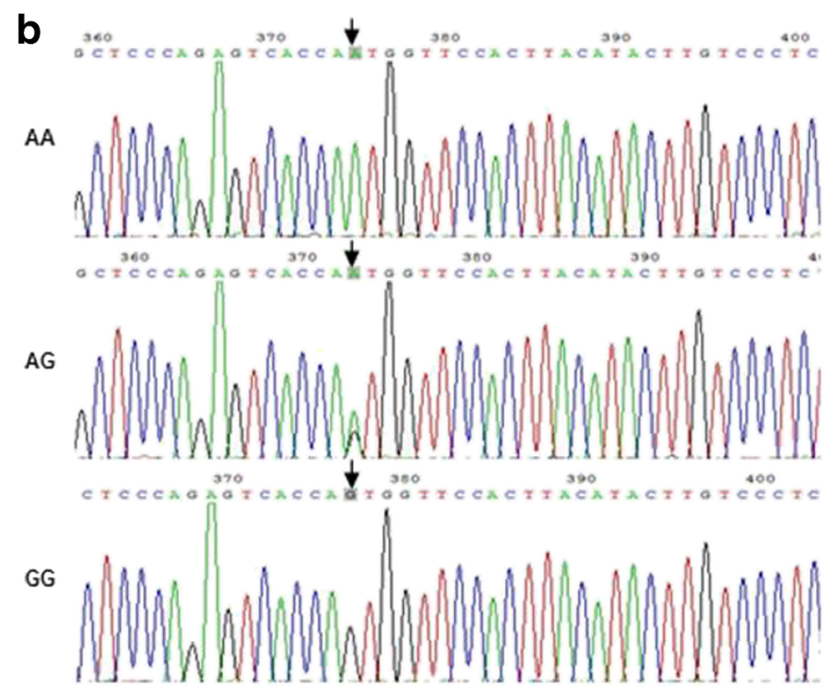

107 bp. b DNA sequencing of the Ser680Asn polymorphisms (AA, AG and GG) as indicated by arrows. The lane marked $M$ is the marker of DNA. The lane marked P is the DNA of PCOS without enzyme digestion 
Table 3 Genotype distribution and allele frequency of FSHR polymorphism

\begin{tabular}{lccc}
\hline Genotype & Cases $(n=215)$ & Controls $(n=205)$ & $p$ value \\
\hline A307T(rs6165) & & & \\
Thr/Thr(AA) & $93(43.3 \%)$ & $91(44.4 \%)$ & 0.133 \\
Ala/Thr(AG) & $95(44.2 \%)$ & $100(48.8 \%)$ & \\
Ala/Ala(GG) & $27(12.6 \%)$ & $14(6.8 \%)$ & \\
H-W test & 0.721 & 0.052 & \\
Allele frequency & & & \\
Ala(G) & $149(15.3 \%)$ & $128(31.5 \%)$ & 0.29 \\
Thr(A) & $281(65.2 \%)$ & $282(69.3 \%)$ & \\
N680S(rs6166) & & & \\
Asn/Asn(AA) & $93(43.3 \%)$ & $94(45.9 \%)$ & 0.069 \\
Ser/Asn(AG) & $94(43.7 \%)$ & $98(47.8 \%)$ & \\
Ser/Ser(GG) & $28(13.0 \%)$ & $13(6.3 \%)$ & \\
H-W test & 0.581 & 0.057 & 0.152 \\
Allele frequency & & & \\
Asn(A) & $280(69.8 \%)$ & $286(69.8 \%)$ & \\
Ser(G) & $150(30.2 \%)$ & $124(30.2 \%)$ & \\
\hline
\end{tabular}

$p$ values from chi-squared test

$H-W$ test $H$ ardy-Weinberg equilibrium test

patients and the controls in Age, Height, Waist, Hip, mF-G score, E2, P, Fasting insulin and CHO (Table 1).

Ala307Thr and Ser680Asn polymorphisms of FSHR were analyzed by PCR-RFLP and DNA sequencing (Figs. 1 and 2). The distribution of FHSR genotypes and allele frequencies in PCOS patients and controls were evaluated (Table 3). The distribution of the polymorphisms was conformed by HardyWeinberg equilibrium test. In PCOS patients, linkage disequilibrium (D') between the Ala307Thr and Asn680Ser of FSHR polymorphisms was $0.932\left(r^{2}=0.831\right)$, indicating a nearcomplete linkage disequilibrium. However, there were no statistical differences in the allele or genotype frequencies of the polymorphisms between the PCOS patients and the controls.
We further analyzed the phenotypes for the Ala307Thr and Ser680Asn polymorphisms in the PCOS patients. There were no statistical differences among the different obesity standards of the PCOS patients with different FSHR polymorphisms (Table 4). For the endocrine parameters, there were significant differences in the level of FSH among the PCOS patients carrying different genotypes of the two polymorphisms ( $p=$ 0.027 for Ser680Asn; $p=0.009$ for Ala307Thr) and in the level of PRL among the PCOS patients carrying different genotypes of the Ser680Asn polymorphisms $(p=0.009)$ (Table 5). There were no statistical differences in LH, LH/ FSH, E2, P and T. Moreover, no statistical difference was found in the clinical pregnancy rate among the PCOS patients carrying different genotypes of the two polymorphisms (Fig. 3).

\section{Discussion}

It has been known that PCOS is a hereditary endocrine disease. With changes of living environment and increase of social pressure, the incidence of PCOS gradually increases during recent years. The clinical manifestations of PCOS patients appear diverse in different geographic regions and among different races. Up to date, knowledge about PCOS has been mainly obtained from the studies involving Western populations. A recent study comparing 547 Chinese women with 427 Dutch women revealed some differences in the phenotypic characteristics of PCOS between the two ethnic groups [21]. In this study, we assessed the baseline characteristics between the PCOS patients ( $n=215)$ and the controls $(n=205)$ in the Han ethnic of Shanxi Province in north China. We observed increased levels of Weight, BMI, WHR, LH, LH/FSH, T, Fasting glucose, HOMA-IR and TG and decreased levels of Menarche age, FSH, PRL, HDL and LDL in the PCOS patients.

As a complex hereditary endocrine disease, analyses of major genes associated with PCOS have been attempted for

Table 4 FSHR polymorphisms versus different obesity standards in PCOS patients

\begin{tabular}{|c|c|c|c|c|c|c|c|c|}
\hline & \multicolumn{4}{|l|}{ Ala307Thr } & \multicolumn{4}{|l|}{ Ser680Asn } \\
\hline & $\mathrm{AA}(n=93)$ & $\mathrm{AG}(n=95)$ & GG $(n=27)$ & $p$ value & $\mathrm{AA}(n=93)$ & $\mathrm{AG}(n=94)$ & GG $(n=28)$ & $p$ value \\
\hline \multicolumn{9}{|l|}{ BMI } \\
\hline$<18.5$ & $9(52.9 \%)$ & $6(35.3 \%)$ & $2(11.8 \%)$ & \multirow[t]{4}{*}{0.68} & $6(50.0 \%)$ & $3(25.0 \%)$ & $3(25.0 \%)$ & \multirow[t]{4}{*}{0.66} \\
\hline $18.5-24$ & $29(36.2 \%)$ & $42(52.5 \%)$ & $9(11.2 \%)$ & & $33(41.8 \%)$ & $35(44.3 \%)$ & $11(13.9 \%)$ & \\
\hline $24-28$ & $35(45.5 \%)$ & $31(40.3 \%)$ & $11(14.3 \%)$ & & $29(40.8 \%)$ & $32(45.1 \%)$ & $10(14.1 \%)$ & \\
\hline$>28$ & $20(48.8 \%)$ & $16(39.0 \%)$ & $5(12.2 \%)$ & & $25(47.2 \%)$ & $24(45.3 \%)$ & $4(7.5 \%)$ & \\
\hline \multicolumn{9}{|l|}{ WHR } \\
\hline$<0.85$ & $31(48.4 \%)$ & $29(45.3 \%)$ & $4(6.2 \%)$ & \multirow[t]{2}{*}{0.18} & $35(47.9 \%)$ & $34(46.6 \%)$ & $4(5.5 \%)$ & \multirow[t]{2}{*}{0.06} \\
\hline$>0.85$ & $62(41.4 \%)$ & $66(43.7 \%)$ & $23(15.2 \%)$ & & $58(40.8 \%)$ & $60(42.3 \%)$ & $24(16.9 \%)$ & \\
\hline
\end{tabular}

$p$ values from chi-squared test on the different genotypes of FSHR polymorphisms 
Table 5 FSHR polymorphisms versus endocrine parameters in PCOS patients

\begin{tabular}{|c|c|c|c|c|c|c|c|c|}
\hline & \multicolumn{4}{|l|}{ Ala307Thr } & \multicolumn{4}{|l|}{ Ser680Asn } \\
\hline & $\mathrm{AA}(n=93)$ & $\mathrm{AG}(n=95)$ & GG $(n=27)$ & $p$ value & $\mathrm{AA}(n=93)$ & $\mathrm{AG}(n=94)$ & GG $(n=28)$ & $p$ value \\
\hline FSH (mIU/ml) & $7.07 \pm 2.54$ & $7.48 \pm 1.77$ & $13.22 \pm 16.64$ & 0.009 & $7.12 \pm 2.55$ & $7.57 \pm 1.89$ & $13.71 \pm 17.46$ & 0.027 \\
\hline LH (mIU/ml) & $7.19 \pm 4.48$ & $7.88 \pm 5.78$ & $7.53 \pm 4.71$ & 0.823 & $7.14 \pm 4.45$ & $7.22 \pm 4.69$ & $8.45 \pm 4.89$ & 0.445 \\
\hline LH/FSH & $1.11 \pm 0.81$ & $1.09 \pm 0.79$ & $0.89 \pm 0.60$ & 0.539 & $1.06 \pm 0.66$ & $0.99 \pm 0.65$ & $0.99 \pm 0.63$ & 0.924 \\
\hline $\mathrm{E} 2(\mathrm{pg} / \mathrm{ml})$ & $55.60 \pm 15.43$ & $55.32 \pm 34.72$ & $53.77 \pm 19.81$ & 0.301 & $55.59 \pm 15.57$ & $56.32 \pm 32.99$ & $52.55 \pm 20.21$ & 0.415 \\
\hline $\mathrm{P}(\mathrm{ng} / \mathrm{ml})$ & $1.30 \pm 5.52$ & $2.61 \pm 11.32$ & $4.65 \pm 14.05$ & 0.718 & $1.31 \pm 5.64$ & $0.79 \pm 2.00$ & $0.44 \pm 0.13$ & 0.927 \\
\hline $\mathrm{T}(\mathrm{ng} / \mathrm{dl})$ & $60.19 \pm 29.37$ & $51.91 \pm 28.34$ & $44.76 \pm 24.86$ & 0.115 & $59.40 \pm 29.85$ & $53.69 \pm 27.62$ & $45.52 \pm 25.05$ & 0.282 \\
\hline PRL (ng/ml) & $17.20 \pm 15.68$ & $12.07 \pm 7.38$ & $16.55 \pm 6.46$ & 0.052 & $17.73 \pm 15.69$ & $11.70 \pm 6.93$ & $17.01 \pm 6.80$ & 0.009 \\
\hline
\end{tabular}

$p$ values from ANOVA test on the different genotypes of FSHR polymorphisms

better understanding of the etiology of the disease. Since it plays an important role in FSH signal transduction, FSHR has been extensively studied including its gene structure. The polymorphisms at the 307 and 680 loci on exon 10 of FSHR have become an attracting topic in recent years. A study from Shanghai, a metropolitan city in southeast China, showed a significant association between PCOS patients and Ser680Asn but not Ala307Thr polymorphisms of FSHR in the Han ethnic women [15]. To investigate whether this observation also exists in different geographic regions of China, we recruited patients with the same Han ethnic from Shanxi Province in north China. However, we failed to observe any association between PCOS patients and the Ser680Asn polymorphisms of FSHR. Our results are consistent with a recently reported study conducted in Xi'an, a city near Shanxi Province within the same north China region [16] and a study performed in a different geographic region (Netherlands) and with different ethnical women (Caucasian) [5]. Therefore, studies using different ethnical populations and/or conducted in different geographic regions may lead to different results of the interrelationship between FSHR polymorphisms and PCOS.

Obesity and abdominal adiposity are typical clinical manifestations of PCOS patients. It has been reported that approximately $50 \%$ of PCOS women are overweight or obese and most of them have the abdominal phenotype [22]. Based on BMI and WHR, the criteria used for obesities [23, 24], we investigated whether there was a correlation between obesity and the FSHR polymorphisms in PCOS patients. We have observed no correlation between the different obesity standard of PCOS patients and the genotypes of FSHR polymorphism. A panel of endocrine hormones was analyzed in relation to the genotypes of Ala307Thr and Ser680Asn polymorphisms in the PCOS patients. We have observed that the both FSHR polymorphisms were related to the level of FSH. In addition, the result showed that the Ser680Asn polymorphism was correlated with the level of PRL. Interestingly, there was no significant difference between the clinical pregnancy rate and the different genotypes of FSHR polymorphisms.

In conclusion, our results indicate that there is no association between the Ala307Thr and Ser680Asn polymorphisms of FSHR and PCOS patients in Han ethnical population from Shanxi Province in north China. In addition, the FSHR polymorphisms are associated with the levels of FSH and PRL.
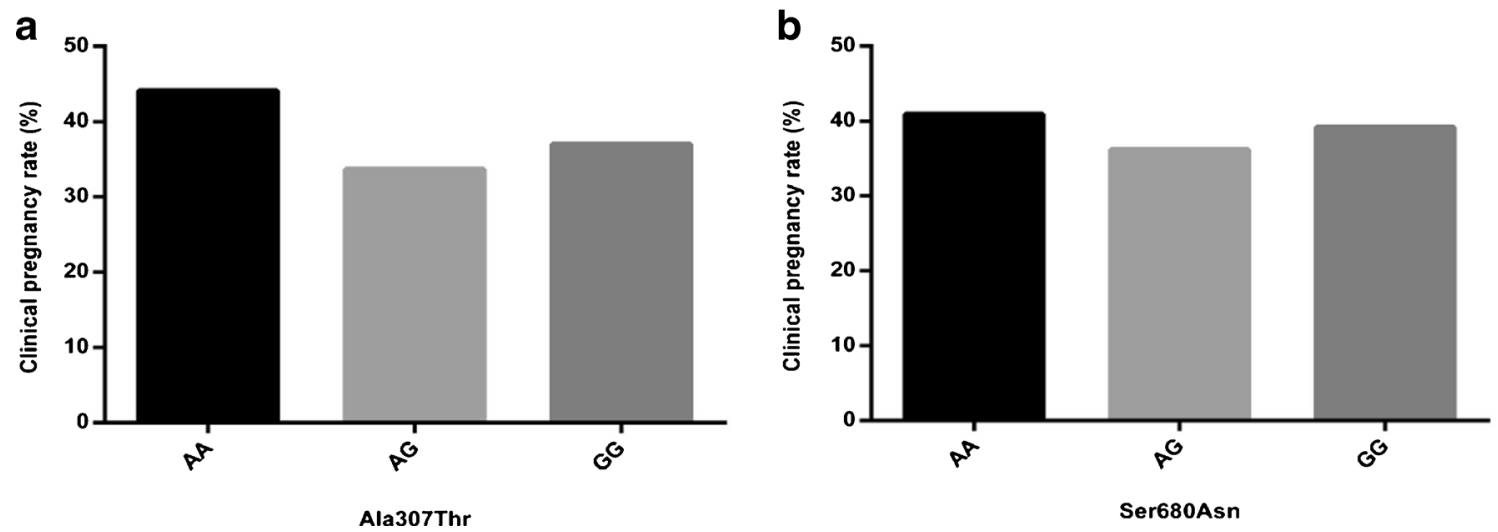

Fig. 3 Clinical pregnancy rate of PCOS patients carrying different FSHR polymorphisms 
Acknowledgments The authors would sincerely thank all subjects and all medical staff who participated in this study. Furthermore, we are very grateful to Mr. Luo, of the department of urology of University of Iowa for correcting the manuscript. This study was supported by the international science and technology cooperation project in Shanxi Province (2011081070) and the overseas returnee research fund in Shanxi province (2010).

Open Access This article is distributed under the terms of the Creative Commons Attribution License which permits any use, distribution, and reproduction in any medium, provided the original author(s) and the source are credited.

\section{References}

1. Franks S. Polycystic ovary syndrome. N Engl J Med. 1995;333(13): 853-61.

2. The Rotterdam ESHRE/ASRM-Sponsored PCOS Consensus Workshop Group. Revised 2003 consensus on diagnostic criteria and long-term health risks related to polycystic ovary syndrome. Fertil Steril. 2004;81(1):19-25.

3. Shen Y, Wang L, Zhao Y, You L, Geng L, Gu HF, et al. Evaluation of the association between GHR exon 3 polymorphism and polycystic ovary syndrome among Han Chinese women. Growth Hormon IGF Res. 2011;21(5):248-51.

4. Zhang CW, Zhang XL, Xia YJ, Cao YX, Wang WJ, Xu P, et al. Association between polymorphisms of the CYP11A1 gene and polycystic ovary syndrome in Chinese women. Mol Biol Rep. 2012;39(8):8379-85.

5. Valkenburg O, Uitterlinden AG, Piersma D, Hofman A, Themmen $\mathrm{AP}$, de Jong FH, et al. Genetic polymorphisms of GnRH and gonadotrophic hormone receptors affect the phenotype of polycystic ovary syndrome. Hum Reprod. 2009;24(8):2014-22.

6. Gu BH, Park JM, Baek KH. Genetic variations of follicle stimulating hormone receptor are associated with polycystic ovary syndrome. Int J Mol Med. 2010;26(1):107-12.

7. Fauser BC, Van Heusden AM. Manipulation of human ovarian function: physiological concepts and clinical consequences. Endocr Rev. 1997;18(1):71-106.

8. Gromoll J, Pekel E, Nieschlag E. The structure and organization of the human follicle-stimulating hormone receptor (FSHR) gene. Genomics. 1996;35(2):308-11.

9. Laven JS, Mulders AG, Suryandari DA, Gromoll J, Nieschlag E, Fauser BC, et al. Follicle-stimulating hormone receptor polymorphisms in women with normogonadotropic anovulatory infertility. Fertil Steril. 2003;80(4):986-92.

10. Simoni M, Nieschlag E, Gromoll J. Isoforms and single nucleotide polymorphisms of the FSH receptor gene: implications for human reproduction. Hum Reprod Update. 2002;8(5):413-21.
11. Perez Mayorga M, Gromoll J, Behre HM, Gassner C, Nieschlag E, Simoni M. Ovarian response to follicle-stimulating hormone (FSH) stimulation depends on the FSH receptor genotype. J Clin Endocrinol Metab. 2000;85(9):3365-9.

12. Lussiana C, Guani B, Mari C, Restagno G, Massobrio M, Revelli A. Mutations and polymorphisms of the FSH receptor (FSHR) gene: clinical implications in female fecundity and molecular biology of FSHR protein and gene. Obstet Gynecol Surv. 2008;63(12):785-95.

13. Dolfin E, Guani B, Lussiana C, Mari C, Restagno G, Revelli A. FSHreceptor Ala307Thr polymorphism is associated to polycystic ovary syndrome and to a higher responsiveness to exogenous FSH in Italian women. J Assist Reprod Genet. 2011;28(10):925-30.

14. Unsal T, Konac E, Yesilkaya E, Yilmaz A, Bideci A, Ilke Onen H, et al. Genetic polymorphisms of FSHR, CYP17, CYP1A1, CAPN10, INSR, SERPINE1 genes in adolescent girls with polycystic ovary syndrome. J Assist Reprod Genet. 2009;26(4):205-16.

15. Du J, Zhang W, Guo L, Zhang Z, Shi H, Wang J, et al. Two FSHR variants, haplotypes and meta-analysis in Chinese women with premature ovarian failure and polycystic ovary syndrome. Mol Genet Metab. 2010;100(3):292-5.

16. Fu L, Zhang Z, Zhang A, Xu J, Huang X, Zheng Q, et al. Association study between FSHR Ala307Thr and Ser680Asn variants and polycystic ovary syndrome (PCOS) in Northern Chinese Han women. J Assist Reprod Genet. 2013;30(5):717-21.

17. Archer JS, Chang RJ. Hirsutism and acne in polycystic ovary syndrome. Best Pract Res Clin Obstet Gynaecol. 2004;18(5): 737-54.

18. Xu X, Shi Y, Cui Y, Ma J, Che L, Chen ZJ. Endocrine and metabolic characteristics of polycystic ovary syndrome in Chinese women with different phenotypes. Clin Endocrinol. 2012;76(3):425-30.

19. Sundblad V, Chiauzzi VA, Escobar ME, Dain L, Charreau EH. Screening of FSH receptor gene in Argentine women with premature ovarian failure (POF). Mol Cell Endocrinol. 2004;222(1-2):53-9.

20. Sudo S, Kudo M, Wada S, Sato O, Hsueh AJ, Fujimoto S. Genetic and functional analyses of polymorphisms in the human FSH receptor gene. Mol Hum Reprod. 2002;8(10):893-9.

21. Guo M, Chen ZJ, Eijkemans MJ, Goverde AJ, Fauser BC, Macklon NS. Comparison of the phenotype of Chinese versus Dutch Caucasian women presenting with polycystic ovary syndrome and oligo/amenorrhoea. Hum Reprod. 2012;27(5):1481-8.

22. Gambineri A, Pelusi C, Vicennati V, Pagotto U, Pasquali R. Obesity and the polycystic ovary syndrome. Int J Obes Relat Metab Disord. 2002;26(7):883-96.

23. World Health Organization (WHO). Waist circumference and waisthip ratio: report of a WHO expert consultation, Geneva, 8-11 December 2008. Geneva: WHO; 2011.

24. China's Ministry of Health Control Department. Guideline on the prevention and control of overweight and obesity among Chinese adults (try-out). Beijing: People's Medical Publishing House; 2003. 